\title{
An assessment of genetic diversity among Camellia sinensis L. (cultivated tea) and its wild relatives based on randomly amplified polymorphic DNA and organelle-specific STS
}

\author{
FRANCIS N. WACHIRA†, WAYNE POWELL \& ROBBIE WAUGH* \\ Department of Cell and Molecular Genetics, Scottish Crop Research Institute, Invergowrie, Dundee DD2 5DA, \\ Scotland, U.K.
}

\begin{abstract}
Members of the genus Camellia interbreed relatively freely and several natural species hybrids exist. Species introgression into the cultivated germplasm of tea, Camellia sinensis L. (O. Kuntz), from related Camellia species has been postulated, and it is thought that teas currently under cultivation are not archetypal varieties. Randomly amplified polymorphic DNAs (RAPDs) and organelle-specific polymerase chain reactions were used to establish the affinities among cultivated tea and its wild relatives. The measures of similarity obtained indicated that RAPDs were taxonomically informative in Camellia, and the species relationships revealed were generally consistent with those obtained using morphological, compatibility and terpenoid affinities. Species-specific RAPD products and products potentially diagnostic of introgressive hybridization into the cultivated gene pool were identified. The organellar genomes were remarkably conserved, with polymorphism detected in only one of four noncoding regions in the chloroplast and mitochondrial genomes.
\end{abstract}

Keywords: Camellia spp., gene introgression, phenetics, randomly amplified polymorphic DNA, similarity.

\section{Introduction}

A fundamental goal of germplasm collection and conservation is the understanding of genetic relationships within and between the species of concern. A good understanding is critical for the effective organization and management of such germplasm collections. In plant breeding programmes, estimates of genetic relationships can be useful for the identification of parents for hybridization, and for reducing the number of accessions needed to maintain a broad range of genetic variability. The genus Camellia is composed of over 80 taxa (Sealy, 1958), of which only one, $C$. sinensis L. (O. Kuntz), is currently used commercially as a source of the beverage tea. The potential for economic use of other species as a beverage is, however, real, and

\footnotetext{
*Correspondence. E-mail: rwaugh@scri.sari.ac.uk †Permanent address: Tea Research Foundation of Kenya, PO Box 820, Kericho, Kenya.
}

several, including C. taliensis, C. grandibractiata, $C$. kwangsiensis, C. gymnogyna, C. crassicolumna, $C$. tachangensis, $C$. ptilophylla and $C$. irrawadiensis, are already used in parts of Asia (Chang \& Bartholomew, 1984). In addition, seed from $C$. japonica and C. oleifera have been widely used for oil extraction in Japan and China, respectively (Sealy, 1958), and most Camellia spp. are of great ornamental value.

During the past century, a number of studies have examined the relationships between Camellia species in cultivation (Sealy, 1958; Chang \& Bartholomew, 1984 and references cited therein; Chuangxing, 1988; Tien-Lu, 1992). In general, morphological characters, phytochemicals and terpenoids have been used. However, it has been argued that these may not reflect the true level of genetic differentiation, as most are subject to large environmental effects. Leaf terpenoids have, nevertheless, proved useful in analysing closely related species (Takeo, 1983; Nagata, 1986; Owuor et al., 1987; McDowell et al., 1995), but at higher levels of classification they are considered to be less useful owing to convergence 
and reticulate evolution. Ackerman (1973) and Takeda (1990) have evaluated cross-compatibility of several Camellia species to determine their phenetic relationships. Because most species within the genus hybridize freely, several species complexes have been formed that have ultimately made evaluation of relationships even more daunting. Several minor taxa have been treated as conspecific with major taxa, although more recently accumulated evidence has shown that these minor taxa have no natural distribution and are derived from hybridization events involving different species (Parks et al., 1967; Uemoto et al., 1980). By analysing for the presence and distribution of phytochemicals (e.g. eugenol glycoside, sasanquin and fluorescent flavonoid sulphates) in a wide range of Camellia species and their hybrids, Parks et al. (1981) were able to demonstrate the introgression of $C$. japonica traits into $C$. sasanqua giving hybrids that were treated as a distinct species (C. hiemalis) by Chang (1981).

Two of the major monographers of the genus, Sealy (1958) and Chang (Chang \& Bartholomew, 1984), have identified two patterns of species relationships with very different arrangements of subgenera and generic sections. The more recent of these studies (Chang \& Bartholomew, 1984) has recognized Camellia as comprising two interfertile ancestor groups. Ancestor group 1 comprises one distinct subgeneric group, Camellia, and a second ill-defined complex group, Protocamellia. Ancestor group 2 is represented by two distinct subgenera, Thea and Metacamellia. The subgenus Protocamellia has morphological characteristics of all the other three subgenera but does not merit treatment as a distinct genus (Chang \& Bartholomew, 1984). The subgenus Thea has eight sections, one of which (section Thea) comprises cultivated tea (Chang \& Bartholomew, 1984; Chuangxing, 1988). Tien-Lu (1992), however, recognized only seven sections in the subgenus Thea. It has been proposed that all Camellia have a common ancestor and evolved from the primitive Protocamellia in two distinct directions, one for Thea and Metacamellia and the other for Camellia (Chang \& Bartholomew, 1984).

Species compatibility studies within the genus have shown that most interspecific (inter-and intrasectional as well as intrageneric) crosses can be made without much difficulty, although some groups are more compatible than others (Ackerman, 1973; Takeda, 1990). This provides opportunities for breeders to exploit the wide germplasm of Camellia by looking at other species for traits of interest in their breeding endeavours. Knowledge of genetic relationships between tea and the other related species is, therefore, vital for the efficient selection of parents for interspecific hybridization.

Molecular markers, such as the restriction fragment length polymorphisms (RFLPs) and randomly amplified polymorphic DNAs (RAPDs), provide an efficient means of estimating genetic relationships (Ecke \& Michaelis, 1990; Miller \& Tanksley, 1990; Jung et al., 1993). Because of their simplicity, RAPDs have been widely used in establishing relationships within and between different species (Adams \& Demeke, 1993; Ratnaparkhe et al., 1995; Yamagishi, 1995; Hoey et al., 1996; Orozco-Castillo et al., 1996). In Camellia sinensis, RAPDs have been demonstrated to be useful in genotype differentiation within cultivated germplasm (Wachira et al., 1995). Variation in chloroplast (cp) and mitochondrial (mt) DNAs has been used to examine relationships among distantly related taxa (Waugh et al., 1990; van de Ven et al., 1993; Olmstead \& Palmer, 1994). These studies have been simplified by the design of consensus primers that can be used in PCR to amplify homologous regions in different species and have proved to be highly informative (Taberlet et al., 1991; Demesure et al., 1995). Here, we report the use of RAPD markers and PCR amplification of chloroplast and mitochondrial sequences to assess relationships among cultivated tea and allied wild species of the genus Camellia. The results obtained have been compared with existing information based on cross-compatibility and morphological markers used mostly in present-day taxonomy.

\section{Materials and methods}

\section{Plant material}

Twenty Camellia species belonging to eight sections of the genus Camellia were used in this study (Table $1)$. These included nine tea cultivars $(C$. sinensis) and two closely related wild species, $C$. irrawadiensis and $C$. taliensis. A total of 28 genotypes were evaluated.

\section{DNA isolation and PCR amplification}

DNA was isolated using the modified method of Gawel \& Jarret (1991) as described by OrozcoCastillo et al. (1994). RAPD reactions were conducted on individual DNA samples as described by Wachira et al. (1995). Numerous adjustments were initially examined in order to optimize the RAPD assay to achieve the necessary reproducibility and resolution for all Camellia spp. The arbitrary sequence 10 -mer primers used were either obtained 
Table 1 Camellia genotypes studied and their taxonomic affinities*

\begin{tabular}{|c|c|c|c|}
\hline Subgenus & Section & Species & Source \\
\hline Camellia & $\begin{array}{l}\text { Camellia } \\
\text { Paracamellia } \\
\text { Oleifera } \\
\text { Furfuracea }\end{array}$ & $\begin{array}{l}\text { C. pitardii } \\
\text { C. saluensis } \\
\text { C. brevistyla } \\
\text { C. kissi } \\
\text { C. miyagii } \\
\text { C. tenuiflora } \\
\text { C. oleifera } \\
\text { C. sasanqua } \\
\text { C. furfuracea }\end{array}$ & $\begin{array}{l}\text { NRIVOT, Japan } \\
\text { NRIVOT, Japan } \\
\text { NRIVOT, Japan } \\
\text { NRIVOT, Japan } \\
\text { NRIVOT, Japan } \\
\text { NRIVOT, Japan } \\
\text { NRIVOT, Japan } \\
\text { NRIVOT, Japan } \\
\text { NRIVOT, Japan }\end{array}$ \\
\hline Protocamellia & Archecamellia & C. granthamiana & NRIVOT, Japan \\
\hline Metacamellia & $\begin{array}{l}\text { Camelliopsis } \\
\text { Theopsis }\end{array}$ & $\begin{array}{l}\text { C. assimilis } \\
\text { C. salicifolia } \\
\text { C. fraterna } \\
\text { C. lutchuensis } \\
\text { C. nokoensis } \\
\text { C. rosaeflora } \\
\text { C. tsai }\end{array}$ & $\begin{array}{l}\text { NRIVOT, Japan } \\
\text { NRIVOT, Japan } \\
\text { NRIVOT, Japan } \\
\text { NRIVOT, Japan } \\
\text { NRIVOT, Japan } \\
\text { NRIVOT, Japan } \\
\text { NRIVOT, Japan }\end{array}$ \\
\hline Thea & Thea & $\begin{array}{l}\text { C. irrawadiensis } \\
\text { C. taliensis } \\
\text { C. sinensis (var. sinensis) Yabukita } \\
\text { C. sinensis (var. assamica) AK1296 } \\
\text { C. sinensis (var. assamica) URLC1 } \\
\text { C. sinensis (var. sinensis) TJL4 } \\
\text { C. sinensis (var. assamica) B6/61 } \\
\text { C. sinensis (var. assamica) S15/10 } \\
\text { C. sinensis (var. sinensis) 56/89 } \\
\text { C. sinensis (var. sinensis) K/Purple } \\
\text { C. sinensis (var. assamica) BB21 }\end{array}$ & $\begin{array}{l}\text { TRFK, Kenya } \\
\text { NRIVOT, Japan } \\
\text { NRIVOT, Japan } \\
\text { NRIVOT, Japan } \\
\text { PBI, U.K. } \\
\text { PBI, U.K. } \\
\text { PBI, U.K. } \\
\text { TRFK, Kenya } \\
\text { TRFK, Kenya } \\
\text { TRFK, Kenya } \\
\text { TRFK, Kenya }\end{array}$ \\
\hline
\end{tabular}

*After Chang (1981).

NRIVOT, National Research Institute of Vegetables, Ornamental Plants and Tea; TRFK, Tea Research Foundation of Kenya; PBI, Plant Breeding International.

from Operon Technologies (Almeda, CA, U.S.A.) or were synthesized at the Scottish Crop Research Institute on an Applied Bio-Systems 392 PCR-mate oligonucleotide synthesizer. The 39 informative primers finally screened and chosen for analysis are listed in Table 2a. Some organelle-specific universal primers listed in Table $2 \mathrm{~b}$ were used to amplify homologous noncoding regions of the mtDNA and cpDNA. PCRs were performed as for RAPD, but with different annealing temperatures (shown in Table 2b). All PCR products were fractionated in agarose gels and visualized as described previously (Wachira et al., 1995). Amplified $\mathrm{cp}$ and mtDNA products were screened for insertions, deletions and substitutions by digestion with 11 restriction enzymes. The enzymes used were HaeIII, RsaI, MspI, TaqI, AvaI, BamHI, EcoRI, AccI, HinfI, SmaI and DraI.

(c) The Genetical Society of Great Britain, Heredity, 78, 603-611.

\section{Data analyses}

RAPD bands were scored for presence (1) or absence $(0)$. Only data from intensely stained unambiguous polymorphic bands were used for statistical analysis. Bands of similar size but with intensity differences were not included in the analysis. Measures of similarity (Nei \& $\mathrm{Li}, 1979$ ) and principal coordinate analyses were derived with the GENSTAT 5 (1987) statistical package.

\section{Results and discussion}

\section{RAPDS}

Of 45 decamer primers screened on a subset of four Camellia sinensis genotypes, 39 consistently produced the same multiband fingerprints. These 
Table 2a Primers used for the detection of polymorphism in Camellia species and their sequences

\begin{tabular}{|c|c|c|c|}
\hline Primer & Sequence & Primer & Sequence \\
\hline SC10-01 & 5'-GGTAGCAGTC-3' & OPR-05 & $5^{\prime}$-GACCTAGTGG-3' \\
\hline SC10-12 & 5'-GTTTCCGGTG-3' & OPR-20 & 5'-ACGGCAAGGA-3' \\
\hline SC10-19 & 5'-CGTCCGTCAG-3' & OPU-15 & 5'-ACGGGCCAGT-3' \\
\hline SC10-97 & 5'-TCCGGCTTTC-3' & OPU-20 & $5^{\prime}$-ACAGCCCCCA-3' \\
\hline OPA-09 & 5'-GGGTAACGCC-3' & OPB-03 & 5'-СТСССТGCAA-3' \\
\hline OPB-10 & $5^{\prime}$-CTGCTGGGAC-3' & OPV-14 & $5^{\prime}$-AGATCCCGCC-3' \\
\hline OPD-08 & 5'-GTGTGCCCCA-3' & OPV-15 & 5'-CAGTGCCGGT-3' \\
\hline OPG-09 & 5'-CTGACGTCAC-3' & OPV-20 & $5^{\prime}$-CAGCATGGTC- $3^{\prime}$ \\
\hline OPH-09 & 5'-TGTAGCTGGG-3' & OPW-01 & $5^{\prime}$-CTCAGTGTCC-3' \\
\hline OPI-04 & 5'-CCGCCTAGTC-3' & OPW-02 & 5'-ACCCCGTCAA-3' \\
\hline OPJ-05 & $5^{\prime}$-CTCCATGGGG-3' & OPW-04 & $5^{\prime}$-CAGAAGCGGA-3' \\
\hline OPJ-07 & 5'-CСТСТCGACA-3' & OPW-06 & 5'-AGGCCCGATG-3' \\
\hline OPK-15 & 5'-CTCCTGCCAA-3' & OPW-11 & $5^{\prime}$-CTGATGCGTG-3' \\
\hline OPL-01 & $5^{\prime}$-GGCATGACCT-3' & OPW-14 & 5'-CTGCTGAGCA-3' \\
\hline OPM-14 & 5'-AGGGTCGTTC-3' & OPW-18 & $5^{\prime}$-TTCAGGGCAC- $3^{\prime}$ \\
\hline OPN-03 & 5'-GGTACTCCCC-3' & OPX-08 & $5^{\prime}$-CAGGGGTGGA-3 \\
\hline OPQ-10 & 5'-TGTGCCCGAA-3' & OPX-09 & 5'-GGTCTGGTTG-3' \\
\hline OPQ-12 & 5'-AGTAGGGCAC-3' & OPX-17 & 5'-GACACGGACC-3' \\
\hline OPQ-15 & 5'-GGGTAACGTG-3' & OPY-06 & 5'-AAGGCTCACC-3' \\
\hline OPR-03 & $5^{\prime}$-ACACAGAGGG-3' & & \\
\hline
\end{tabular}

Table 2b Primer sequences used to amplify specific chloroplast and mitochondrial regions of the Camellia genome

\begin{tabular}{|c|c|c|c|}
\hline Region amplified & $\begin{array}{l}\text { Primer } \\
\text { name }\end{array}$ & Sequence & $\begin{array}{c}\text { Annealing } \\
\text { temperature } \\
\left({ }^{\circ} \mathrm{C}\right)\end{array}$ \\
\hline - V7 region mt rDNA & $\begin{array}{l}\text { Mt-P1V7 } \\
\text { Mt-P2V7 }\end{array}$ & $\begin{array}{l}\text { 5'-TATGAACAACAAACCTGTCTTTAACGGGATGG-3' } \\
\text { 5'-GCGGACTTGACGTCATCCCCACCTTCCTCCAG-3' }\end{array}$ & 53 \\
\hline cp-trn L (UAA) intron & $\begin{array}{l}\text { Intron } 1 \\
\text { Intron } 2\end{array}$ & $\begin{array}{l}\text { 5'-CGAAATCGGTAGACGCTACG-3' } \\
\text { 5'-GGGGATAGAGGGACTTGAAC-3' }\end{array}$ & 54 \\
\hline $\begin{array}{l}\mathrm{cp}-t r n \mathrm{~L}(\mathrm{UAA})-t r n \mathrm{~F}(\mathrm{GAA}) \\
\text { Intergenic region }\end{array}$ & $\begin{array}{l}\text { Rus } 7 \\
\text { Rus } 8\end{array}$ & $\begin{array}{l}\text { 5'-GGTTCAACTCCCTCTATCCC-3' } \\
\text { 5'-AATTGAACTGGTGACACGAG-3' }\end{array}$ & 54 \\
\hline $\begin{array}{l}\mathrm{cp}-t r n \mathrm{~T}(\mathrm{UGU})-t r n \mathrm{~L}(\mathrm{UAA}) \\
\text { Intergenic region }\end{array}$ & $\begin{array}{l}\text { Inter A } \\
\text { Inter B }\end{array}$ & $\begin{array}{l}\text { 5'-CATTACAAATGCCATCGTCT-3' } \\
\text { 5'-TCTACCGATTTCGCCATATC-3' }\end{array}$ & 54 \\
\hline
\end{tabular}

were then used to screen the 28 genotypes listed in Table 1 . Consistently well-amplified products ranged in size from 0.3 to $2.3 \mathrm{~kb}$. Figure 1 shows a typical example of the polymorphism generated. A total of 197 unambiguous polymorphic bands were scored in the 28 genotypes. We could not exclude the possibility that different-sized DNA fragments contained homologous DNA sequences or that similar-sized products were nonhomologous. In addition, we did not attempt to confirm that the amplified fragments were exclusively generated from nuclear DNA. Measures of similarity based on single-linkage cluster analysis and principal coordinate analysis were used to examine the data. These measures have been strongly recommended for RAPDs, as the use of numerous random characters results in errors of homology or mis-scoring being accounted for as 'noise' in the analyses. Genetic similarity within the nine cultivated genotypes of Camellia sinensis ranged from 0.48 to 0.82 (results not shown). The tea accessions studied therefore exhibit extensive RAPD variation, which is consistent with an earlier study (Wachira et al., 1995). Within the wild Camellia germplasm, the similarity coefficients ranged

(C) The Genetical Society of Great Britain, Heredity, 78, 603-611. 
Fig. 1 RAPD profiles of Camellia species generated with primer OPV-14 (5'-AGATCCCGCC-3').
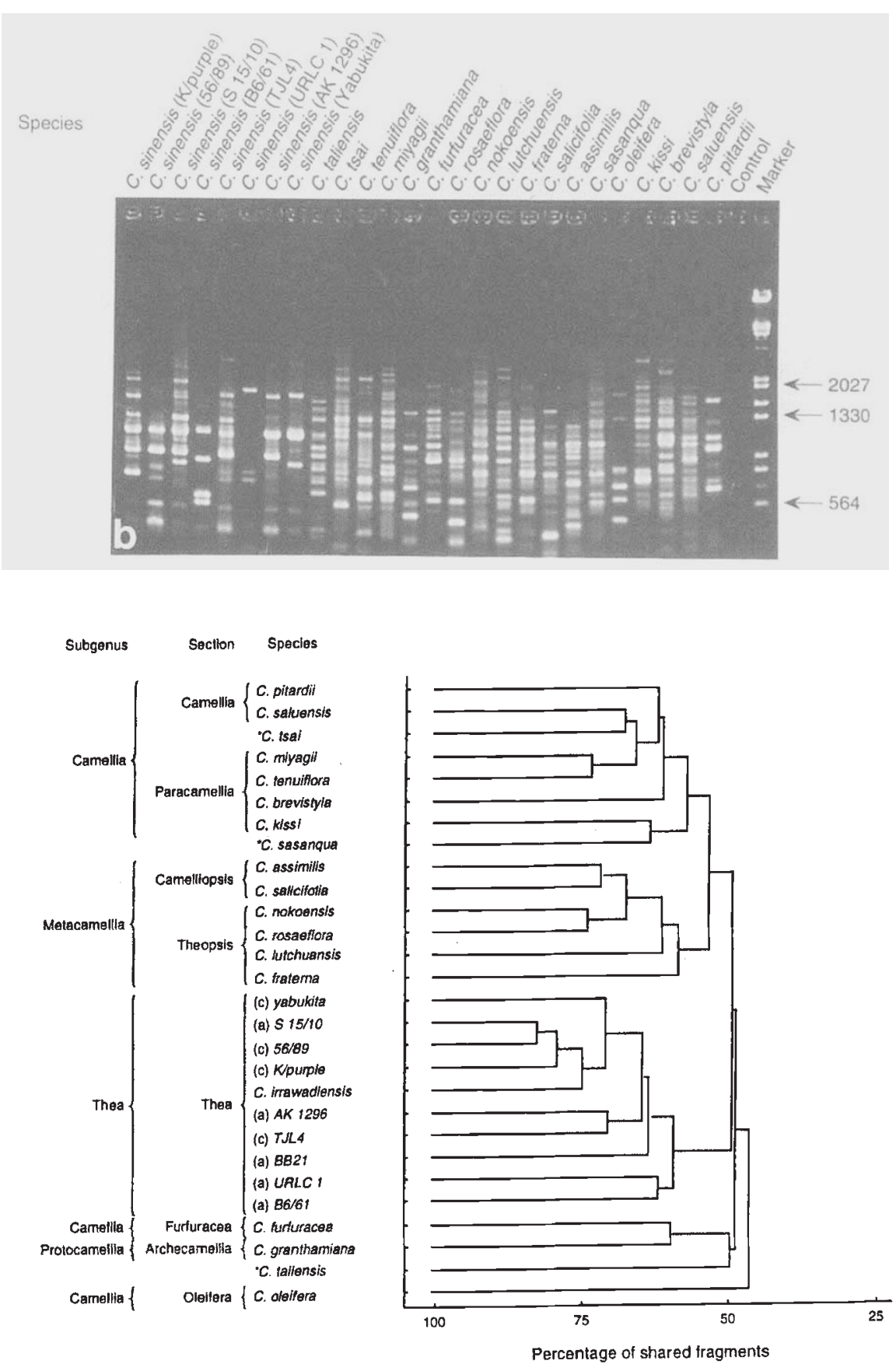

Fig. 2 A dendrogram of the relationships based on RAPD data between 28 taxa of Camellia derived from average linkage cluster analysis. ${ }^{*}$ These species did not cluster in their expected groups. mellia subgenera, do, however, suggest that these groups may be unstable and that a larger data set is required to increase the overall robustness of the analysis. Given this, it is not surprising that the topology of the dendrogram indicates substantial overlap between different species within the genus. However, Camellia oleifera was noticeably discrete, constituting a major branch of the dendrogram. Camellia furfuracea, C. granthamiana and C. taliensis classified in sections Furfuracea, Archecamellia and 
Oleifera, respectively, formed a clade, which joined the subgeneric groups Camellia, Metacamellia and Thea at 50 per cent similarity. Camellia taliensis was, however, the most dissimilar member of this group. Species of section Thea separated from the Metacamellia/Camellia subgeneric subgroups at 53 per cent similarity. Camellia irrawadiensis, a wild tea not traditionally cultivated for the production of leaf tea, was clustered ( 76 per cent similarity) with $C$. sinensis var. sinensis accession $\mathrm{K} / \mathrm{Purple}$, a commercial tea clone that contains the purple/brick red anthocyanin plant pigments characteristic of $C$. irrawadiensis. Cultivar K/Purple is most probably a natural hybrid between $C$. sinensis var. sinensis and $C$. irrawadiensis (our personal observations). Some species hybrids, at least those involving tea and $C$. irrawadiensis, are known to exist in the wild in parts of Burma and some may have found their way into the cultivated germplasm undetected because of their superficial morphological similarity (Wight \& Barua, 1957; Wood \& Barua, 1958).

Intersectional crosses undertaken by Ackerman (1973) revealed that three species of section Paracamellia hybridized readily among themselves, indicating a close relationship, which was typical of ecospecies. Section Paracamellia, however, has one of the greatest distributional areas in the genus Camellia and would be expected to be associated with greater diversity. RAPD markers indeed revealed extensive polymorphism within the group. Ackerman's (1973) work, however, involved the three species, $C$. kissi, $C$. oleifera and $C$. sasanqua, whose taxonomy has since been revised (Chang \& Bartholomew, 1984). In the present study, C. kissi grouped closely with $C$. sasanqua (see Fig. 1), although both are now classified in sections Paracamellia and Oleifera, respectively. Although species of section Theopsis also grouped closely, crosses within the section are often difficult, reflecting behaviour typical of cenospecies and suggesting the existence of genetic isolation barriers usually associated with more distant crosses (Ackerman, 1973). This is strange because the group has a very narrow distribution (Chang \& Bartholomew, 1984).

To evaluate the relationships between sectional and subgeneric groups, grouped data analysis was performed. Similarity values (Nei \& Li, 1979) ranged from 62.3 per cent between sections Theopsis and Camelliopsis to 46.4 per cent between sections Thea and Archecamellia. The similarities between the other sectional groups were almost equal (50-58.9 per cent). An UPGMA dendrogram derived from the grouped data analysis shows section Thea as discrete, constituting a major branch of the dendrogram (Fig. 3). Separation of species of section Thea from the rest of the members of genus Camellia has also been demonstrated by studies on flavanol patterns (Nagata, 1986). Only members of Thea in the entire genus contain galloyled catechins, such as (-)-epicatechin gallate and (-)-epigallocatechin gallate. Similarly, only this group contains caffeine (although $C$. kissi contains trace amounts). The amino acid, theanine, is also only present in the leaves of section Thea.

Even given the potentially low resolution of the dendrogram (revealed as short internode branches), sections Camellia and Paracamellia as well as sections Theopsis and Camelliopsis cluster into separate groups. This result is presented graphically in the form of a principal coordinate plot (PCO) in Fig. 4 in which the first two principal components accounted for 35.2 per cent of the total variation. All the sections generally group according to their supposedly related taxa. Sections Theopsis and Camelliopsis (the latter also known as Eriandra) clustered to form the subgenus, Metacamellia. In the translation of Chang's monograph, Chang \& Bartholomew (1984) noted that species of these two closely related sections shared many highly derived characteristics. Results presented here also suggest that the subgenus Thea has strong affinity to the subgenus Metacamellia and more so to section Theopsis than Camelliopsis, an observation also noted by Chang \& Bartholomew (1984). Section Archecamellia was the most distant section from Thea and probably the most ancestral. Based on analysis of morphological

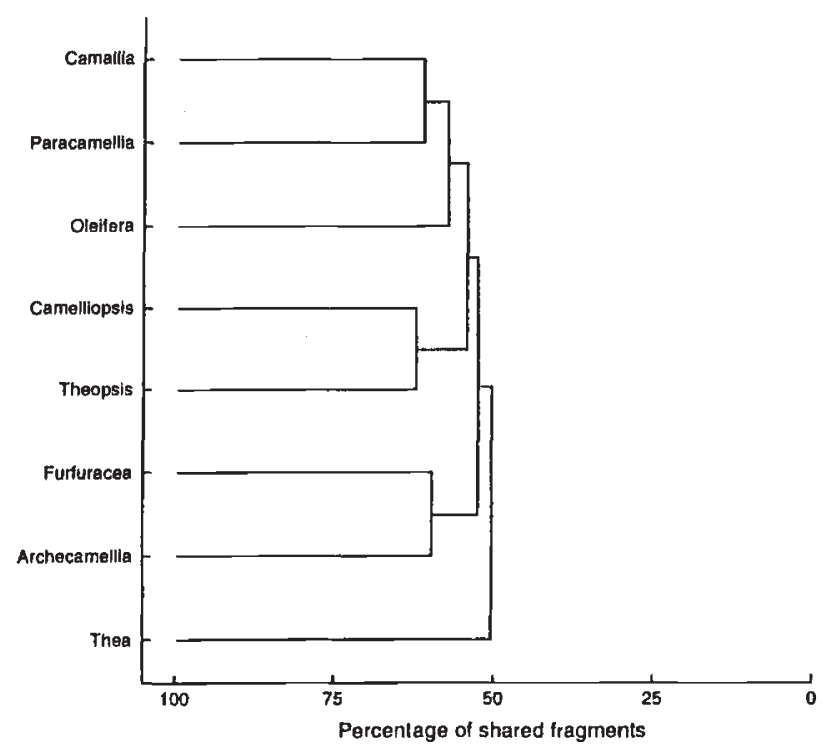

Fig. 3 A dendrogram of eight sections of genus Camellia derived by average linkage cluster analysis. 


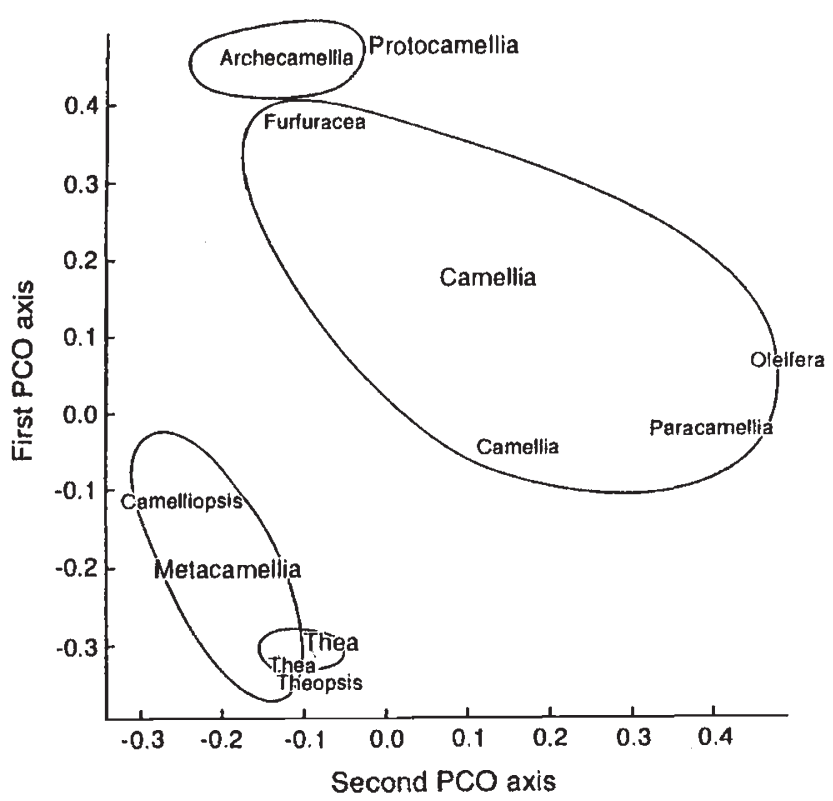

Fig. 4 A principal coordinate plot of eight sections of the genus Camellia (based on a reduced similarity matrix).

First and second principal components accounted for 35.2 per cent of the total variation.

differentiation and species distribution, Tien-Lu (1992) has suggested that Thea evolved from section Archecamellia of subgenus Protocamellia. Sections Furfuracea, Camellia, Paracamellia and Oleifera were grouped to form the large subgenus Camellia. The PCO analysis indicates that, although the sectional groups of the subgenus Camellia were dispersed, they were clearly distinct from the others and could therefore be grouped. The dispersion may reflect the size and diversity of the subgenus, which is the largest and most widely grown.

RAPDs, therefore, appear to provide useful information on genetic relatedness at the sectional level in Camellia. The results presented here indicate that these are in the decreasing order: Thea - Theopsis - Camelliopsis - Camellia - Paracamellia - Oleifera - Furfuracea - Archecamellia. This is in general agreement with relationships derived by the use of compatibility studies (Takeda, 1990; Ackerman, 1993). However, Thea species hybridize more easily with Camelliopsis than with Theopsis (Ackerman, 1973; Takeda, 1990), which may indicate a closer affinity between these sections.

RAPDs have been widely used in phenetic studies in different species, e.g. Coffea (Orozco-Castillo et al., 1996), Juniperus (Adams \& Demeke, 1993), Pisum (Hoey et al., 1996), Beta (Jung et al., 1993), Cajanus (Ratnaparkhe et al., 1995), Lentil (Sharma et al., 1995) and Lilium (Yamagishi, 1995). Overall, the results from these and other studies have conformed closely to those derived from nuclear and chloroplast RFLPs, isozymes, cytogenetic analysis and morphological affinities.

A single RAPD, OPN-03-1400, which was diagnostic of species of section Thea used here, was identified (data not shown). Such diagnostic markers are important for strain identification and cultivar characterization and can be used to detect instances of natural interspecific gene introgression. Sectionspecific RAPD markers have been identified in Lilium (Yamagishi, 1995). In such an internally mixed genus like Camellia, species-specific markers will be important in determining the flow of genetic material via species introgression. Here, products that are specific to species of other sections and that are only present in tea ( $C$. sinensis) at low frequency may be candidates for further analyses of interspecific gene flow in Camellia. Such products include bands OPV-03-700 and OPW-18-700, both of which were present in all species of sections Camelliopsis and Theopsis but only present in two genotypes of section Thea $(C$. irrawadiensis and $C$. sinensis accession K/Purple). Further analysis with more species will, however, be required to establish fully the specificity of loci to particular taxa and subsequent interspecific gene flow into tea.

\section{Organellar DNA}

Because of their relative resistance to evolutionary change, compared with nuclear DNA, cpDNA and mtDNA sequences have been widely used to investigate interspecific relationships (Jorgensen \& Cluster, 1989; Waugh et al., 1990; van de Ven et al., 1993; Olmstead \& Palmer, 1994). Noncoding regions display higher rates of evolution than coding regions and are, therefore, desirable targets for phylogenetic studies. The resolution of many such noncoding regions has been improved by PCR amplification with universal primers (Taberlet et al., 1991; Demesure et al., 1995) and subsequent direct sequencing. However, the relatively high frequency of insertions/ deletions may even, in some cases, make it possible to use the size of PCR product as a genetic marker. The choice of $\mathrm{cp} / \mathrm{mtDNA}$ regions that maximize phylogenetic information is, however, dependent on the evolutionary timescale of the plant system being studied. The four noncoding regions of the $\mathrm{cp}$ and mt genomes amplified with universal primers did not reveal any size polymorphic products in Camellia. A 980 bp product was amplified for the $\operatorname{trn}$ T(UGU) tmL(UAA) intergenic spacer, $410 \mathrm{bp}$ and $200 \mathrm{bp}$ products from the trm $\mathrm{L}(\mathrm{UAA}) 3^{\prime}$ exon and 
trnF(GAA), respectively, and a 600 bp product from the $\mathrm{V} 7$ region of mtrDNA. When the amplified products were screened for insertions, deletions and substitutions by digestion with 11 restriction enzymes, no polymorphism was revealed. Only one cpDNA PCR product revealed a single-strand conformation polymorphism (SSCP) (results not shown). This SSCP in the intergenic spacer between the $\operatorname{trn} L(\mathrm{UAA}) 3^{\prime}$ exon and $\operatorname{tr} F(\mathrm{GAA})$ indicated that $C$. furfuracea (section Furfuracea), $C$. assimilis (section Camelliopsis), C. nokoensis and C. tsaii (both of section Theopsis) shared a common haplotype. The implications of this observation are not clear, although it may indicate possible hybridization between species of the sections involved. SSCP is based upon secondary and tertiary structural conformational differences in single-stranded DNA (Orita et al., 1989). The resolution of SSCPs is, however, limited by the size of fragment - the larger it is, the more difficult it is to be resolved effectively. The fragment resolved by SSCP in this study was the smallest. The exact mutational changes responsible for generating the SSCPs were, however, not determined, and it is possible that different events have resulted in a similar SSCP profile. The amplified products will have to be sequenced to determine their precise relationships. A limitation in the use of cpDNA and mtDNA data is that uniparental inheritance effectively eliminates the systematic analysis of taxa derived from hybridization owing to exclusion of information from one of the parental clones. Nevertheless, the lack of size polymorphic markers, PCR-RFLPs and SSCPs from the $\mathrm{cp}$ and mtDNA regions amplified using universal primers may lend credence to the theory that all Camellia species share a relatively recent and common ancestry.

\section{Conclusions}

Results presented here suggest that RAPDs are phenetically informative in Camellia, with the species affinities described being generally similar to those obtained using morphological, compatibility and terpenoid data. RAPDs, however, provided a greater degree of resolution at the subsectional and subspecies levels. In similar studies, RAPDs have also provided greater resolution than other technologies (Sharma et al., 1995). As RAPDs are abundant, quick to generate, largely reflect unselected genetic alterations, and are not subject to environmental influences, they could provide a useful complement to most traditional and classical systematic characters in Camellia.
This study represents only the first step in using DNA-based markers as a tool to implement studies of molecular systematics in this large genus. The inclusion of additional accessions and other species and the use of an increased number of primers may provide a greater resolution of the affinities among these taxa. Direct sequencing of amplified cpDNA and mtDNA products may also be important for recreating phylogenies.

\section{Acknowledgements}

The authors gratefully acknowledge the supply of some plant material from Dr Yoshiyuki Takeda, NRIVOT, Japan and Dr Peter Jack, PBI, Cambridge, U.K. This project was supported by the Overseas Development Agency through the British Council. The Scottish Crop Research Institute receives grant-in-aid from the Scottish Office Agriculture, Environment and Fisheries Department.

\section{References}

ACKERMAN, w. L. 1973. Species compatibility relationships within the genus Camellia. J. Hered., 64, 356-358.

ADAMS, R. P. AND DEMEKE, T. 1993. Systematic relationships in Juniperus based on random amplified polymorphic DNAs (RAPDs). Taxonomy, 42, 553-571.

CHANG, H. T. 1981. A taxonomy of the genus Camellia. Acta Sci. Nat. University of Sunyatseni, Monog. Series, 1, 1-180.

Chang, H. T. AND Bartholomew, B. 1984. Camellias. B.T. Batsford, London.

ChuAngXing, Y, 1988. The subdivisions of genus Camellia with a discussion on their phylogenetic relationships. Acta Botanica Yunnanica, 10, 61-67 (in Chinese with English summary).

DEMESURE, B., SODZI, N. AND PETIT, R. J. 1995. A set of universal primers for amplification of polymorphic non-coding regions of mitochondrial and chloroplast DNA in plants. Mol. Ecol., 4, 129-131.

ECKE, W. AND MiChaElis, G. 1990. Comparison of chloroplast and mitochondrial DNA from five morphologically distinct Beta vulgaris cultivars: sugar beet, fodder beet, beetroot, foliage beet and Swiss chard. Theor. Appl. Genet., 79, 440-442.

GAWEL, N. J. AND JARRET, R. L. 1991. A modified CTAB DNA extraction procedure for Musa and Ipomoea. $P$. Mol. Biol. Rep., 9, 262-266.

Genstat 5 COMmitTEe. 1987. Genstat 5 Reference Manual. Clarendon Press, Oxford.

HOEY, B. K., CROWE, K. R., JONES, V. M. AND POLANS, N. O. 1996. A phylogenetic analysis of Pisum based on morphological characters and allozyme and RAPD markers. Theor. Appl. Genet., 92, 92-100.

JORGENSEN, R. A. AND Cluster, P. D. 1989. Modes and tempos in the evolution of nuclear ribosomal DNA: 
new characters for evolutionary studies and new markers for genetic and population studies. Ann. Mo. Bot. Gard., 75, 1238-1247.

JUNG, C., PILlen, K., FRESE, S., FAHR, S. AND MELCHINGER, A. E. 1993. Phylogenetic relationships between cultivated tea and wild species of the genus Beta revealed by DNA fingerprinting. Theor. Appl. Genet., 86, 449-457.

McDOWELL, 1., TAYLOR, S. AND GRAY, C. 1995. The phenolic pigment composition of black tea liquours - Part II: Discriminating origin. J. Sci. Food Agric., 69, 475-480.

MILLER, J. C. AND TANKSLEY, S. D. 1990. RFLP analysis of phylogenetic relationships and genetic variation in the genus Lycopersicon. Theor. Appl. Genet., 80, 437-448.

NAGATA, T. 1986. Differences in caffeine, flavanols and amino acids contents in leaves of cultivated species and hybrids in the genus Camellia. Jap. Agric. Res. Quart., 19, 276-280.

NEI, M. AND LI, w. 1979. Mathematical model for studying genetic variation in terms of restriction endonuclease. Proc. Natl. Acad. Sci. U.S.A., 76, 5296-5273.

OlMSTEAD, R. G. AND PALMER, J. D. 1994. Chloroplast DNA and systematics - a review of methods and data analysis. Am. J. Bot., 81, 1205-1224.

ORITA, M., IWAHANA, H., KANAZAWA, H., HAYASHI, K. AND SEKIYA, T. 1989. Detection of polymorphisms of human DNA by gel electrophoresis as single strand conformation polymorphisms. Proc. Natl. Acad. Sci. U.S.A., 81, 2766-2770.

OROZCO-CASTIllo, C., CHALMERS, K. J., WAUGH, R. AND PoWelt, w. 1994. Detection of genetic diversity and selective gene introgression in coffee using RAPD markers. Theor. Appl. Genet., 87, 934-940.

OROZCO-CASTILLO, C., CHALMERS, K. J., POWELl, w. AND WAUGH, R. 1996. RAPD and organelle-specific PCR reaffirms taxonomic relationships within the genus Coffea. Pl. Cell Rep., 15, 337-341.

OWUOR, P. O., TAKEO, T., HORITA, H., TSUSHIDA, T. AND MURAl, T. 1987. Differentiation of clonal teas by Terpene Index. J. Sci. Food Agric., 40, 341-345.

PARKS, C. R., GRIFFITHS, A. AND MONTGOMERY, K. R. 1967. A possible origin of anthocyanin (red) pigmentation in the flowers of Camellia sasanqua. American Camellia Yearbook, 229-242.

PARKS, C. R., KONDO, K. AND SWAIN, T. 1981. Phytochemical evidence for the genetic contamination of Camellia sasanqua. Thunberg. Jap. J. Breed., 31, 168-182.
RATNAPARKHE, M. B., GUPTA, V. S., VEN MURPHY, M. R. AND RANJEKAR, P. K. 1995. Genetic fingerprinting of pigeon pea (Cajanus cajan (L.) Millsp.) and its wild relatives using RAPD markers. Theor. Appl. Genet., 91, 893-898.

SEALY, J. 1958. A Revision of the Genus Camellia. Royal Horticultural Society, London.

SHARMA, S. K., DAWSON, 1. K. AND WAUGH, R. 1995. Relationships among cultivated and wild lentils revealed by RAPD analysis. Theor. Appl. Genet., 91, 647-654.

TABERlet, P., GIelly, L., PAUton, G. AND BOUVET, J. 1991. Universal primers for amplification of three non-coding regions of chloroplast DNA. Plant Mol. Biol, 17, 1105-1109.

TAKEDA, Y. 1990. Cross compatibility of tea (Camellia sinensis) and its allied species in the genus Camellia. Jap. Agric. Res. Quart., 24, 111-116.

TAKEO, T. 1983. Effect of clonal specificity of monoterpene alcohol composition of tea shoots on black tea aroma profile. Jap. Agric. Res. Quart., 17, 120-124.

TIEN-Lu, M. 1992. A revision of Camellia sec. Thea. Acta Botanica Yunnanica, 14, 115-132 (in Chinese with English summary).

Uemoto, s., TANAKA, T. AND FUJEDA, K. 1980. Cytogenetic studies on the origin of Camellia vernalis. I. On the meiotic chromosomes in some related Camellia forms in Hirado Island. J. Jap. Soc. Hort. Sci., 48, 475-482.

VAN DE VEN, W. T. G., DUNCAN, N., RAMSAY, G., PHILLIPS, M., PoWell, W. AND WAUGH, R. 1993. Taxonomic relationships between $V . f a b a$ and its relatives based on nuclear and mitochondrial RFLPs and PCR analysis. Theor. Appl. Genet., 86, 71-80.

WACHIRA, F. N., WAUGH, R., HACKETT, C. A. AND POWELL, w. 1995. Detection of genetic diversity in tea (Camellia sinensis) using RAPD markers. Genome, 38, 201-210.

WAUGH, R., VAN DE VEN, W. T. G., PHILliPS, M. S. AND POWELl, w. 1990. Chloroplast DNA diversity in the genus Rubus (Rosaceae) revealed by Southern hybridisation. Pl. Syst. Evol., 172, 65-75.

Wight, w. AND BARUA, D. N. 1957. What is tea? Nature, 179, 506-507.

wOOD, D. J. AND BARUA, D. N. 1958. Species hybrids of tea. Nature, 181, 1674-1675.

YAMAGISHI, M. 1995. Detection of section specific random amplified polymorphic DNA (RAPD) markers in Lilium. Theor. Appl. Genet., 91, 830-835. 